\title{
Macrotrabecular Hepatoblastoma
}

National Cancer Institute

\section{Source}

National Cancer Institute. Macrotrabecular Hepatoblastoma. NCI Thesaurus. Code C7095.

A pure fetal or fetal and embryonal epithelial hepatoblastoma characterized by the presence of broad trabeculae. 